\title{
The Influence of Parental Feeding Knowledge and Practices on Chinese Children and Adolescents' Weight Status
}

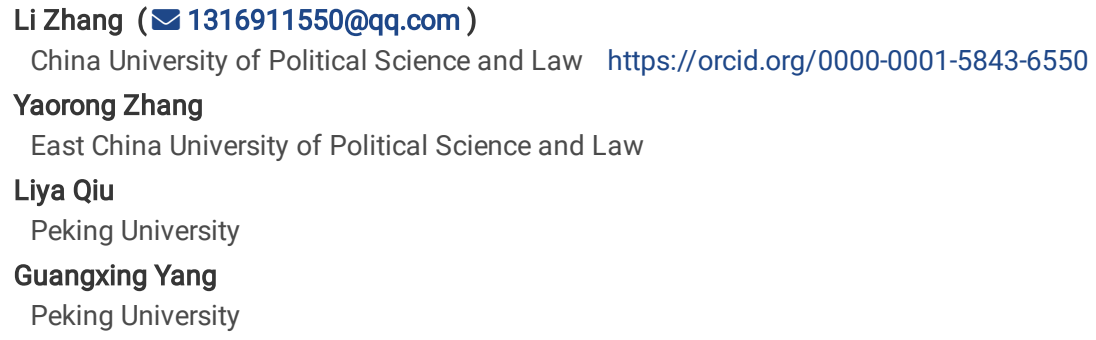

\section{Research}

Keywords: parental feeding practices, urban-rural differences, child and adolescent weight status, China Health and Nutrition Survey (CHNS)

Posted Date: August 18th, 2020

DOl: https://doi.org/10.21203/rs.3.rs-54631/v1

License: () (1) This work is licensed under a Creative Commons Attribution 4.0 International License. Read Full License 


\section{Abstract}

Background: Child and adolescent overweight is becoming more prevalent in recent decades. It is imperative to investigate the determinants of children and adolescents' weight outcomes.

Methods: Through analyzing the 2004, 2006, 2009 and 2011 waves of survey data released by China Health and Nutrition Survey (CHNS), this paper investigated the gender and rural-urban differences in terms of the ways in which parental feeding knowledge and practices affected the weight status of Chinese children and adolescents aged 6 to 17. Data were collected through random sampling strategy and logistic regression models were built to conduct analyses.

Results: The results showed that feeding knowledge and practices varied by parental residence and were different among mothers and fathers. In addition, parental feeding knowledge, parental eating habits and styles, mother's intervention on children's food intakes and physical exercise, and the number of meals parents sharing with children showed significant effects on children and adolescents' weight status.

Conclusions: As compared to fathers, mothers' feeding practices showed more significant effects on children and adolescents' weight status. The manner in which parental feeding practices influenced children and adolescents' weight status also differed in rural and urban settings. These findings suggested that mothers were still "gatekeepers" of children and adolescents' food choices and selection; their feeding practices played a more decisive role on Chinese youth's weight status. The urban-rural differentials highlighted in this research also reminded us that the "one-fits-all" solutions to prevent youth's obesity should be avoided.

\section{Background}

Child and adolescent overweight is becoming more prevalent in recent decades. In the United States, more than one of every three children was overweight or obese in 2012 [1]. In European countries, the corresponding rate ranged from 18.0-57.0\% in 2010 [2]. In 2015-2016, the prevalence of obesity among US children and adolescents reached $18.4 \%$ and $20.6 \%$, respectively [3]. The overweight and obesity rates among Chinese children and adolescents were $9.6 \%$ and $6.2 \%$ in 2012 , respectively, which increased by $113.3 \%$ and $195.2 \%$ as compared to the rates reported in 2002 . According to data released by the World Health Organization (WHO), in 2018 the overweight and obesity rates for Chinese children and adolescents aged 5-19 reached $28.5 \%$ and $11.7 \%$, respectively. Although the overweight and obesity rates among Chinese children and adolescents were lower than those of some developed countries, the increasing speed of overweight and obesity are striking, and China now has the largest number of obese and overweight children and adolescents in the world [4].

Children and adolescents' obesity is related to impaired health and some adult-associated diseases, including type II diabetes, dyslipidemia, hypertension, cardiovascular disease, and orthopedic complications [5]. Overweight children and adolescents have been shown facing challenges of social and psychological problems such as stigmatization and poor self-esteem [6]. Thus, is imperative to investigate the determinants of children and adolescents' weight outcomes. Parental feeding behaviors has been found to influence children's nutritional intakes [7]; parental feeding practices also contributed to the intergenerational transmission of obesity[8]. Thus, parental feeding knowledge and feeding practices have been considered as potentially modifiable risk factors of eating behaviors for children and adolescents. Exploring the prospective relation between parental feeding knowledge and practices and children and adolescents' weight status has become a main focus of recent studies [9-11]. "Feeding practices" has been defined by some scholars as context-specific practices and "goal-directed behavior or strategies parents employ to control what, when, and how much their children eat" [12]. Others stated parental feeding practices as specific behaviors or strategies that parents used to maintain or modify children's dietary intakes [13]. This research considered parental feeding practices as parental eating styles and how parents monitored and restricted children and adolescents' food intakes and physical activities. The next section moved to a review of related literature that guided this research.

\section{Parental Feeding Knowledge And Children And Adolescents' Obesity}

Mothers' knowledge about making healthy food choices for their children was found to be negatively linked to the percent of energy intakes from fat that children consumed [14]. Researchers indicated that mothers with the highest BMls and poor nutritional knowledge were least likely to use health as a criterion for children's food selection [15]. Grier and colleagues pointed out that appropriate parental knowledge on nutrition and food intakes could lower the likelihood of children and adolescents being overweight [16]. It was also found that parents who acknowledged that eating vegetables and fruits was beneficial to health were more likely to purchase such food, which led to lower odds of their children being overweight [17]. Chen [18] added that if parents had healthy feeding knowledge, then their children were more likely to intake eggs, nuts and milk, and were less likely to consume fast food and soft drinks. In short, previous studies provided evidence that healthy parental feeding knowledge influenced children and adolescents' weight status.

\section{Parental Food Intake Styles and Children and Adolescents' Weight Status}

A large body of literature suggested that strong similarities existed between children and their parents in terms of food preferences, food intake patterns and their willingness to try new foods $[19,20]$. Children naturally prefer sweet and salty foods and avoid bitter and sour flavors. They learn about eating by watching the eating habits and food preferences of their primary role models, most times their parents. Children were also found to be more likely to try unfamiliar foods after they had seen their mothers ate this same food [21,22]. Acharya and colleagues found that parents' and children's dietary intakes were highly correlated, especially for fruits, vegetables, sweetened beverages and meats [23]. Obese children tended to have ready access to energy dense food at home, which was especially true if their parents preferred this type of food [24]. In this sense, parental attitudes and styles towards food selection as well as eating behaviors significantly impacted children and adolescents' attitudes towards food choices [25]. Parents who reported a lack of time or money constraints tended to rely upon energy dense fast food, which often led to children and adolescents' overweight [26]. 
Scholars also highlighted the importance of parents sharing meals with their children. Through meal sharing, children learned eating habits and styles from their parents. Parents who created a positive mealtime environment by using constructive mealtime practices (including encouraging food tasting) rather than negative parenting practices (such as hurrying and forcing children to eat) led to more positive child eating behavior and lower body weights [27]. Powell and colleagues found that children whose mothers ate at the same time as they did and ate the same foods as their children were easier to feed and refused less food than children of mothers who did not. Children also displayed less fussy eating behaviors if mealtimes were free of distractions, such as television and toys [28]. In contrast, children and adolescents who had a low frequency of eating meals with their parents often reported frequent sweet beverage consumption, snacking, and eating "on-the-go." Eating "on-the-go" in mothers, emotional eating and eating by the television/late at night in fathers often resulted in a higher risk of children and adolescents being obese [29]. These findings emphasized that parental eating habits and styles are determinants of children and adolescents' weight status.

\title{
Parental Monitoring and Restricting Behaviors and Children and Adolescents' Weight Status
}

There has been an increasing body of research on the role of parenting styles and the risk of obesity in children and adolescents. Authoritative parenting often includes a lot of monitoring and dietary restriction, which was generally found to be linked to a lower risk of children and adolescents' obesity [30]. Some studies found that adolescents with lower BMls also reported eating healthier meals in families that had rules around media and food, such as restricting television watching during dinner or consumption expectations [31]. Indulgent parenting was positively associated with child BMI [32]. Other scholars further classified parental feeding styles into four types: emotional feeding (EF), controlling over eating (COE), instrumental feeding (IF) and prompting/encouragement to eat (PEE) [33]. Studies showed that emotional feeding, prompting/encouragement and control over eating affected the occurrence of obesity in childhood [10]. Food restriction for promoting health was associated with increased consumption of junk food, sweets, and snacks. In contrast, encouraging balance and food variety by parents were associated with increased vegetable consumption and smaller waist circumference. Weight was negatively associated with parental pressure and food restriction for weight control [34]. These findings suggested that parental monitoring and restricting children and adolescents' eating and activity behaviors have significant impacts on children and adolescents' weight status.

The existing analyses, however, had some limitations. First, most studies of parental effects on children and adolescents' weight status have not considered the rural-urban differences in China. China is a country with significant rural-urban gaps in living standards, lifestyles and cultural values [35]. Such differences have caused dissimilar communication patterns between parents and children in these two spheres. Prior research indicated that rural and urban parents showed disparate ways educating children. Rural adolescents were closer to their mothers than their urban counterparts; urban adolescents reported more conflicts with their parents than their rural ones [36]. Considering the rural and urban differences, this research proposed the following two hypotheses:

\section{H1: Urban and rural parents had different feeding knowledge and practices in China;}

\author{
H2: Urban and rural parents' feeding knowledge and practices impacted Chinese children and adolescents' weight status in different manners.
}

The second gap in the literature is a lack of differentiation between mothers' and fathers' influence on Chinese children and adolescents' obesity. Although some research on Western societies has done some pioneer work, the results were not consistent. Some observed significant differences in maternal and paternal feeding practices [37]; but others did not find so [38, 39]. As to the link between parental feeding practices and child and adolescent obesity, Zhang and associate found no significantly different impacts of parental feeding practices on child weight status [40]. But others indicated that mothers had a stronger influence over their children's weight and were more concerned about their children's eating behaviors; fathers only played a role in imposing child feeding practices [41]. In addition, mothers' parenting styles, feeding practices, modeling and encouraging of healthful behaviors were found to have stronger impacts on adolescents' BMI z-scores, dietary patterns, physical activity habits and unhealthy weight control behaviors as compared to fathers [42, 43]. The eating behaviors of mothers were shown to be more important predictors of children's body size than eating behaviors of fathers [29]. Other research, nevertheless, showed fathers' parenting style being more significantly linked to more fruit and vegetable intakes along with lower BMI among daughters [44]. Given the differentials documented above, this research proposed two hypotheses for testing among Chinese children and adolescents:

H3: Chinese mothers and fathers had different feeding knowledge and practices;

H4: Mothers' and fathers' feeding knowledge and practices impacted Chinese children and adolescents' weight status in different manners.

\section{Data, Variables And Methods}

\section{Data}

Data used for this analysis came from the China Health and Nutrition Survey (CHNS), an ongoing collaborative project between the Carolina Population Center at the University of North Carolina at Chapel Hill and the National Institute of Nutrition and Food Safety at the Chinese Center for Disease Control and Prevention. Since 1989, the CHNS has collected individual, household, and community level data to assess changes in health, nutrition, and family planning behaviors and outcomes. Surveys have been conducted every two to four years across multiple provinces and municipal cities in China. The CHNS has collected data on a total of 388 communities, 11,130 households, and 42,829 individuals.

In 2004, CHNS began using different questionnaires for adults and children to collect more detailed information about their household commitments, physical activity, food and drink consumption, and mass media exposure. Since year 2004, CHNS introduced these questionnaires for children and adolescents. This research therefore used data only from the 2004, 2006, 2009 and 2011 CHNS surveys. The sample consisted of children and adolescents who were 6 to 17.9 years old when surveys were collected, for a total of 4,960 children and adolescents (1,158 urban and 3,420 rural). The sample covered 11 provinces of China, which well represents children and adolescents in China. 


\section{Variables}

Dependent Variable. The dependent variable was children and adolescent's weight status. The research based this measure on children and adolescents' BMI, which was calculated by the formula: $\mathrm{BMl}=$ weight $(\mathrm{kg}) /$ height $\left(\mathrm{m}^{2}\right)$. The Center for Disease Control and Prevention (CDC) recommends using percentiles as cut-offs to define children's overweight status. Those children whose BMI values are at the 20th percentile, at the 85th to the 95 th percentile and above the 95th percentile are considered as being at the risk of underweight, being at the risk of overweight, and being overweight, respectively. In this analysis, the child's or adolescent's weight status was operationalized to a dependent variable which was called overweight/at risk of overweight. We considered those children and adolescents whose BMI values above the 95th percentile or whose BMI values at the 85th to the 95th percentile as being overweight or at the risk of being overweight. Those children and adolescents were coded as " 1 " and "0" if otherwise.

Independent Variables. As far as the independent variables measuring parental feeding knowledge and feeding practices, three sets of variables were applied in the analysis. The first set of variables examined parental feeding knowledge, which included measures asking whether mothers and fathers agreed eating the following types of food is beneficial to health: (1) fruits and vegetables, (2) sugar, (3) a combination of different types of food, (4) high energy food, (5) a large amount of staple food, (6) less meat, and (7) milk and dairy food, and (8) bean product. The answers were five scales: $1=$ strongly disagree, $2=$ disagree, $3=$ neutral, 4 = agree, and 5 = strongly agree.

The second set of variables measured parental eating habits and styles. The research included questions that asked whether mothers/fathers preferred to eat the following food: (1) fast food, (2) snacks, (3) fruits and (4) vegetables. The answers included five scales: $1=$ strongly dislike, $2=$ dislike, $3=$ neutral, $4=$ prefer, and $5=$ strongly prefer. There was also a question asking the frequency of parents having soft drinks. The answers included five scales as well: $1=$ never, 2 = once a month, $3=1-2$ times a week, $4=3-4$ times a week, and $5=$ everyday. Parental energy intake variables were also included as parental eating style measures.

Parental control over children and adolescents' eating and physical activities were applied as the third set of parental feeding practice measures. Since the CHNS did not survey fathers on these questions, this part of the analysis only showed results for mothers. The third set of variables came from a couple of questions asking if mothers encouraged children/adolescents to (1) control the amount of food they ate, and (2) adjust physical activity level based on weight status. The variables were coded as " 1 " if mothers encouraged the above eating behaviors and physical activities, and " 0 " if otherwise. Meanwhile, the research also incorporated variables measuring the number of days parents shared breakfast, lunch and dinner with their children during the past three consecutive days when the survey was conducted.

Control Variables. The study also controlled for characteristics of children/adolescents and parents. For children/adolescents, the study controlled for their age, gender and residence. For parents, the analysis controlled for parental BMI, education and per capita family income. Descriptive information of all variables discussed above was presented in Table 1.

\section{Methods}

To examine the influence of parental feeding knowledge and practices on children and adolescents' overweight status, the research applied descriptive analysis strategy and the logistic regression to conduct the analysis. The Logistic regression equation can be expressed as follows:

$\operatorname{logit}(P)=\beta_{0}+\beta_{1} X_{1}+\beta_{2} X_{2}+\ldots+\beta_{P} X_{P}$

Where $\mathrm{P}$ represents the occurrence of children and adolescents' obesity/overweight, $\beta_{0}$ is the constant, $\beta_{\mathrm{P}}$ is the partial regression coefficient for the $\mathrm{P}^{\text {th }} \mathrm{X}$.

\section{Results}

\section{Descriptive Results}

Tables 1 and 2 presented the descriptive information of all variables for father's and mother's feeding knowledge and practices, respectively. As Table 1 showed, the average BMI for studied children and adolescents was 17.9, with urban sample's BMI higher than that of rural sample (18.4 vs. 17.7). For all studied sample, the percentages of respondents who were under the risk of being overweight and overweight were $10.0 \%$ and $5.0 \%$, respectively. The percentages of children and adolescents being at the risk of overweight and overweight were both higher among urban respondents as compared to their rural counterparts ( 12.3 vs. $8.9 \% ; 6.2 \%$ vs. $4.5 \%)$.

As to parental feeding knowledge, most parents reported fairly healthy feeding knowledge. For instance, only less than $15.0 \%$ of mothers and fathers disagreed that eating vegetables is beneficial to health. Over $80.0 \%$ of parents agreed that sugar is not good for health. About $70.0 \%$ of parents strongly agreed or agreed that milk and dairy food are healthy food. Close to $60.0 \%$ of parents agreed or strongly agreed that eating a variety of food, and eating less meat and fat is good to health. Over $80 \%$ of the studied parents agreed or strongly agreed that consuming high energy food is not healthy. Overall, mothers and fathers did not show significant differences in terms of their feeding knowledge. Urban parents' feeding knowledge was slightly healthier that of their rural counterparts.

When it comes to parental eating habits and styles, most parents reported healthy eating habits. For example, the percentages of fathers who claimed "liked" and "strongly liked" fruits were $61.0 \%$ and $3.5 \%$, respectively. The corresponding percentages for mothers were $73.4 \%$ and $5.2 \%$, respectively. In addition, the percentages of mothers who reported "liked" and "strongly liked" vegetables were $71.1 \%$ and $4.3 \%$, respectively. The corresponding percentages for mothers were $76.9 \%$ and $5.2 \%$, respectively. The percentages of parents who claimed preferring eating fast food and salted food were low. About $68.7 \%$ of fathers and 
$57.1 \%$ of mothers said that they never drank soft drinks and beverages. In general, no significant rural-urban differences were observed. As compared to fathers, mothers were more likely to eat fruits and vegetables. But mother had higher odds of consuming fast food and salted products. The frequency of mothers drank soft drinks and beverages were also higher than that reported by fathers. As to parental energy intakes, urban parents consumed more food with fat and protein whereas rural parents consumed more food containing energy and carbohydrate. Fathers reported higher energy intakes than mothers.

In terms of parental control of children and adolescents' eating and physical activities, fathers were not asked for these questions and only results for mothers were presented here. The results showed that $76.7 \%$ of urban mothers and $79.8 \%$ of rural mothers did not control the amount of food their children ate. About $57.1 \%$ of urban mothers and $42.8 \%$ of rural mothers claimed that they encouraged their children participating in physical exercises. These findings suggested that urban mothers were more inclined to control their children's eating and activity behaviors than rural mothers.

Regarding parental sharing meals with their children, as compared to urban parents, a higher percentage of rural parents reported sharing meals with their children during the past three consecutive days (.for mothers, for example, $83.0 \%, 85.3 \%$ and $93.0 \%$ vs. $66.7 \%, 65.6 \%$ and $85.1 \%$ ). The percentages of mothers who shared meals with children were higher than those of fathers regardless of residence. The rural and urban differences could be caused by different lifestyles as well as working schedules among rural and urban parents. The relatively tight working schedule may have prevented urban parents from sharing meals with their children.

Overall, the above findings supported the first and third hypotheses. That is, urban and rural parents had different feeding practices; so did mothers and fathers. The differentials for maternal and paternal feeding practices mainly showed in parental eating styles, energy intakes and whether sharing meals with children. The urban and rural differences mainly existed in terms of parental energy intakes and the manner in which parental controlling children and adolescents' eating and activity behaviors. The next part of the analysis continued to test the rest of the other two hypotheses.

[Tables $1 \& 2$ about here]

\section{Logistic Regression Results}

Table 3 presented the logistic regression results of children and adolescents' overweight status on parental feeding knowledge and practice variables. Different models were constructed to differentiate the urban and rural subgroups as well as the mother and father subgroups. Before running logistic regressions, zero-order correlations were performed to exclude variables that had high correlations to prevent the occurrence of multicollinearity. Since variables "eating milk product is beneficial to health" and "eating bean product is beneficial to health" were highly correlated, the former was removed from the regression analysis. Considering the variables representing fat, protein and carbohydrates were highly correlated with the energy variable, and fat, protein and carbohydrates eventually converted to energy, these three variables were removed from the regression analysis. The variables "preferring salty food" and "preferring snack food" were also eliminated from the regression models owing to too many missing values. Due to space constraint, only variables with significant effects on children and adolescents' weight status were discussed here.

As Table 3 showed, after controlling for parental as well as child or adolescent's characteristics, parents agreeing that "eating a variety of food is beneficial to health" significantly lowered the odds of children and adolescents' odds of being overweight. Specifically, with every one level increase in fathers' and mothers' agreeing with such a statement, the odds of children and adolescents being overweight decreased by $16.0 \%\left(e^{-0.18}-1=-0.16\right)$ and $21.0 \%\left(e^{-0.24}-1=-0.21\right)$, respectively. The effects of such a variable on children and adolescents' weight status also varied by residence. For urban mothers, with every one level increase in their agreeing with such a statement, the odds of their children being overweight decreased by $26.0 \%\left(e^{-0.30}-1=-0.26\right)$. Such an effect was not significant among rural respondents. In addition, with every one level increase in mothers agreeing that "eating a large amount of staple food is good for health", the odds of their children being overweight increased by $15.0 \%\left(\mathrm{e}^{0.14}-1=-0.15\right)$. Such a significant effect was not shown among fathers. For rural mothers, with every one level increase in agreeing with such a statement, the risk of their children being overweight rose by $30.0 \%\left(e^{0.26}-1=.30\right)$; no significant impact was found among urban sample. These findings supported $\mathrm{H} 2$ and $\mathrm{H} 4$ that the impacts of parental feeding knowledge and practices on children and adolescents' weight status varied by residence and parents' gender.

Parental eating habits and styles showed significant influence on children and adolescents' weight status. With every one level increase in maternal preference of eating vegetables, the risk of children and adolescents being overweight decreased by $24.0 \%\left(e^{-0.28}-1=-0.24\right)$. No significant effect was observed among fathers. Therefore, $\mathrm{H} 2$ was supported by empirical results. The significant effects of maternal controlling children and adolescents' eating behaviors mainly existed among urban sample. Urban mothers' controlling of children and adolescents' eating behaviors increased the odds of their children being overweight by 1.2 times $\left(e^{0.81}-1=1.20\right)$. Rural mothers' controlling of children's physical activities increased their children's odds of being overweight by $40.0 \%$ ( $e^{0.34}-1=$ 0.40). These results indicated that parental monitoring and controlling of food intakes and physical activates can be considered a behavior that occurred as a result of child and adolescent obesity but not necessarily as an antecedent to obesity [21]. Urban mothers sharing meals with their children was found to have significantly negative influence on children and adolescents' overweight status. Such influence was not significant among rural sample. These results corroborated $\mathrm{H} 4$ that urban and rural differences existed in the relationship between parental feeding practices and children and adolescents' weight status.

Results for the control variables showed that urban sample were more likely to be overweight than their rural counterparts. With age increasing, the odds of children and adolescents being overweight increased. Family income, parental BMI and mother's education had a positive influence on the respondent's overweight status.

[Table 3 about here]

\section{Discussion}


This study relied on analyzing the 2004 to 2011 CHNS survey data to explore whether maternal and paternal feeding knowledge and practices had significantly different effects on Chinese children and adolescents' weight status. The study also concerned if urban and rural parental feeding knowledge and practices differed and had significantly dissimilar effects on children and adolescents' weight status. The general conclusion drawn from the research was that parental feeding knowledge and practices varied by gender and residence. Specifically, food preferences, energy intakes and numbers of meals sharing with children showed different patterns among mothers and fathers. Meanwhile, maternal intervention on children and adolescents' eating and physical activities, parental energy intakes as well as meal sharing also showed rural and urban differences. In addition, the ways in which parental feeding knowledge and practices influenced children and adolescents weight status also differed by residence and gender. Four research hypotheses were all supported by empirical findings.

The results suggested that mothers' feeding knowledge and practices tended to have more substantial influence on children and adolescents' weight status as compared to fathers. Indeed, the rural-urban differences mainly exited among mothers. These findings implied that mothers were still "gatekeepers" of Chinese children and adolescents' food choices and selection. Their feeding knowledge and practices played a more decisive role in determining children and adolescents' weight status. The rural-urban differences found in this research highlighted that rural and urban Chinese families may consider applying dissimilar strategies preventing youth obesity. Not all feeding knowledge and practices had significant effects on children and adolescents' weight status, which reminded us that educators and parents should pay more attention to factors that can effectively reduce obesity prevalence among children and adolescents. Such factors found in this research included encouraging children and adolescents to eat a variety of food, eating more vegetables and fruits, and encouraging parents to share meals with their children. It was found that rural mothers who were more inclined to agree with the statement that "eating a large amount of staple food is not good for health" linked to a greater risk of child and adolescent obesity. This finding seemed to be contradictory to our common sense. This is perhaps because with lower education, rural parents may not be able to appropriately apply their feeding knowledge in practice, which resulted in a higher risk of children and adolescents' obesity. If this is the case, educating parents to turn appropriate feeding knowledge into practice is just as important as conveying healthy feeding knowledge to them.

Parental BMIs were found to be positively related to their children's BMls. It suggested that reducing parental BMls may well be an effective way to reduce risks of their children being obese. Parental education and family income also had positive influence on youth obesity. This finding is different from what have been reported in Western societies where families with higher socioeconomic status tended to have lower obesity prevalence among the youth. In China, families with higher socioeconomic status consume more high-fat and high-energy food and are more likely to have sedentary behaviors, which is considered as a privilege of middle or upper classes $[45,46]$. Thus, children and adolescents with higher socioeconomic status should be the main targets of the obesity prevention programs in China. Mothers in our study were more prone to control the child/adolescent's eating habits and physical activates. Such control behaviors were more likely to be a response to children and adolescents' obesity rather than an antecedent to obesity. Other research echoed our results by showing that the use of restrictive feeding practices was a parental response to the children's unhealthy diet rather than as a result of children's obesity [47, 48].

\section{Conclusion}

The current study provided evidence that parental feeding knowledge and practices had significant influences on Chinese children and adolescents' weight status and such influences varied by parental gender and residence. Parental eating styles and parents sharing meals with children had significant impacts on children and adolescents' obesity, suggesting the importance of cultivating parents to apply appropriate feeding styles. As compared to fathers, mothers' feeding practices had more prominent role on children and adolescents' weight status. Mothers' controlling of the child/adolescent's eating habits and physical activates was more likely to be a response to children and adolescents' obesity rather than an antecedent to obesity. These findings suggested that educating parents to take actions preventing children and adolescents' obesity before it occurs is a crucial task for health care providers and dietitians.

\section{Limitations And Future Research}

There is a lack of longitudinal research examining parental feeding practices and youth obesity. With rapid economic development in China, families started to consume more high fat and energy dense food; people with higher socioeconomic status also reported more sedentary life styles. Hence, it is essential to understand how the impacts of parental feeding practices on youth weight status has been changing over time and further predict its future influences on youth obesity. Further, although this research highlighted the importance of offering dissimilar youth prevention programs to prevent obesity, the study did not offer detailed programs alleviating youth overweight prevalence. Future research may consider developing effective solutions, including parental education programs to prevent children and adolescents from being impaired by obesity.

\section{Abbreviations}

\section{CHNS}

China Health and Nutrition Survey; WHO:World Health Organization; BMl:Body Mass Index; EF:emotional feeding; COE:controlling over eating; IF:instrumental feeding; PEE:prompting/ encouragement to eat; CDC:The Center for Disease Control and Prevention.

\section{Declarations}

\section{Acknowledgements}

This research uses data from China Health and Nutrition Survey (CHNS). We thank the National Institute for Nutrition and Health, China Center for Disease Control and Prevention, Carolina Population Center (P2C HD050924, T32 HD007168), the University of North Carolina at Chapel Hill, the NIH (R01-HD30880, 
DK056350, R24HD050924, and R01-HD38700) and the NIH Fogarty International Center (D43TW009077, D43 TW007709) for financial support for the CHNS data collection and analysis files from 1989 to 2015 and future surveys, and the China-Japan Friendship Hospital, Ministry of Health for support for CHNS 2009, Chinese National Human Genome Center at Shanghai since 2009, and Beijing Municipal Center for Disease Prevention and Control since 2011.

\section{Funding}

Not applicable.

\section{Availability of data and materials}

The data that support the findings of this study are available from The China Health and Nutrition Survey, but restrictions apply to the availability of these data, which were used under license for the current study, and so are not publicly available. Data are however available from the authors upon reasonable request and with permission of The China Health and Nutrition Survey.

\section{Authors' contributions}

LZ designed the study, cleaned and analyzed the data, interpreted the data, and drafted and revised the manuscript; YRZ conducted literature review and cleaned data; QLY made contributions to data acquisition and analyses; YGX contributed to design of the research. All authors conceived the analyses, and approved the final manuscript.

\section{Ethics approval and consent to participate}

Data of this study was from the China Health and Nutrition Survey (CHNS). CHNS was approved by the Institutional Review Committees of the University of North Carolina at Chapel Hill and the National Institute of Nutrition and Food Safety, Chinese Center for Disease Control and Prevention.

\section{Consent for publication}

Not applicable.

\section{Competing interests}

The authors declare there are no conflicts of interest to report.

\section{References}

1. Ogden CL, Carroll MD, Kit BK, et al. Prevalence of childhood and adult obesity in the United States, 2011-2012. JAMA-Journal of the American Medical Association. 2014;311:806-14.

2. Wijnhoven TMA, van Raaij JMA, Spinelli A, et al. WHO European Childhood Obesity Surveillance Initiative: Body mass index and level of overweight among 6-9-year-old children from school year 2007/2008 to school year 2009/2010. BMC Public Health. 2014;14:3108-24.

3. Hales C, Carroll M, Fryar C, et al. Prevalence of Obesity Among Adults and Youth: United States, 2015-2016. NCHS Data Brief. In: Statistics NCfH, editor. National Center for Health Statistics: Hyattsville, MD 2017.

4. Lin D, Fang HY, Zhao LY, et al. Study on the relationship between family-related facotrs and obesity of children and adolescents aged 6-17 years. Chinese Journal of Epidemiology (Zhongguo Lixing Bingxue Zazhi). 2018;39:720-23.

5. Sanyaolu A, Okorie C, Qi X, et al. Childhood and Adolescent Obesity in the United States: A Public Health Concern. Global Pediatric Health. 2019;6:1-11.

6. Swallen KC, Reither EN, Haas SA, et al. Overweight, Obesity, and Health-Related Quality of Life among Adolescents: the National Longitudinal Study of Adolescent Health. Pediatrics. 2005;115:340-47.

7. Vollmer RL, Mobley AR. Parenting styles, feeding styles, and their influence on child obesogenic behaviors and body weight. A review. Appetite. 2013;71:232-41.

8. Sleddens EFC, Kremers SPJ, De Vries NK, et al. Relationship between parental feeding styles and eating behaviours of Dutch children aged 6-7. Appetite. 2010;54:30-6.

9. El-Behadli AF, Sharp C, Hughes SO, et al. Maternal depression, stress and feeding styles: Towards a framework for theory and research in child obesity. Br J Nutr. 2015;113:55-71.

10. Demir D, Bektas M. The effect of childrens' eating behaviors and parental feeding style on childhood obesity. Eat Behav. 2017;26:137-42.

11. Bootsa SB, Tiggemanna M, Corsinib N. Three broad parental feeding styles and young children's snack intake. Health Education Journal. 2017;76:60921.

12. Steinsbekk S, Belsky J, Wichstrøm L. Parental Feeding and Child Eating: An Investigation of Reciprocal Effects. Child Dev. 2016;87:1538-49.

13. Hughes SO, Frankel LA, Beltran A, et al. Food parenting measurement issues: Working group consensus report. Children Obesity. 2013;9:95-102.

14. Matheson D, Robinson T, Varady A, et al. Do Mexican-American mothers' food-related parenting practices influence their children's weight and dietary intake? J Am Diet Assoc. 2006;106:1861-65.

15. Contento I, Zybert P, Williams S. Relationship of cognitive restraint of eating and disinhibition to the quality of food choices of Latina women and their young children. Prev Med. 2005;40:326-36. 
16. Grier SA, Mensinger J, Huang SH, et al. Fast-Food Marketing and Children's Fast-Food Consumption: Exploring Parents' Influences in an Ethnically Diverse Sample. Journal of Public Policy Marketing. 2007;26:221-35.

17. Hill AJ. Developmental Issues in Attitudes to Food and Diet. Proceedings of the Nutrition Society. 2002; 61: $259-66$.

18. Chen WJ. Parental Feeding Knowledge and Children's Food Intakes and Behaviors. Anhui Medical University: Anhui 2011.

19. Aguirre T, Hudson DB, Weber K, et al. Mexican American mothers' eating and child feeding behaviors. Issues in Comprehensive Pediatric Nursing. 2012;53:4-23.

20. Scaglioni S, Salvioni M, Galimberti C. Influence of parental attitudes in the development of children eating behaviour. Br J Nutr. 2008;99(suppl 1):22-5.

21. Stang J, Loth KA. Parenting Style and Child Feeding Practices: Potential Mitigating Factors in the Etiology of Childhood Obesity. J Am Diet Assoc. 2011;6:1301-05.

22. Hingle M, Beltran A, O'Connor T, Thompson D, Baranowski J, Baranowski T. A model of goal directed vegetable parenting practices. Appetite. 2012;58:444-49.

23. Acharya K, Feese M, Franklin F, et al. Body mass index and dietary intake among Head Start children and caregivers. Journal of American Dietetic Association. 2011;111:1314-21.

24. Manios Y, Moschonis G, Grammatikaki E, et al. Determinants of childhood obesity and association with maternal perceptions of their children's weight status: The GENESIS study. J Am Diet Assoc. 2010;110:1527-31.

25. Vereecken C, Maes L. Young children's dietary habits and associations with the mothers' nutritional knowledge and attitudes. Appetite. 2010;54:44-51.

26. Pockock M, Trivedi D, Wills W, et al. Parental perceptions regarding healthy behaviours for preventing overweight and obesity in young children: a systematic review of qualitative studies. Obes Rev. 2009;11:338-53.

27. Kitzmann KM, Beech BM. Family-based interventions for pediatric obesity: Methodological and conceptual challenges from family psychology. Couple Family Psychology: Research Practice. 2011;1:45-62.

28. Powell F, Farrow C, Meyer C, et al. The importance of mealtime structure for reducing child food fussiness. Maternal Child Nutrition. 2017 ; 13.

29. Hajna S, LeBlanc PJ, Faught BE, et al. Associations between family eating behaviours and body composition measures in peri-adolescents: Results from a community based study of school-aged children. Can J Public Health. 2014;5:e15-21.

30. Maliszewski G, Gillette MD, Brown C, et al. Parental Feeding Style and Pediatric Obesity in Latino Families. Hispanic Health Care International. 2017;15:65-70.

31. Verzeletti C, Maes L, Santinello M, et al. Soft drink consumption in adolescence: Associations with food-related lifestyles and family rules in Belgium Flanders and the Veneto Region of Italy. Eur J Pub Health. 2010;20:312-17.

32. Hennessy E, Hughes S, Goldberg J, et al. Parent behavior and child weight status among a diverse group of underserved rural families. Appetite. 2010;54:369-77.

33. Wardle J, Sanderson S, Guthrie C, et al. Parental feeding style and the inter-generational transmission of obesity risk. Obes Res. 2002;10:453-62.

34. Entin A, Kaufman-Shriqui V, Naggan L, et al. Parental Feeding Practices in Relation to Low Diet Quality and Obesity among LSES Children. J Am Coll Nutr. 2014;33:306-14.

35. Yang SH. Urban and Rural Lives: A Sociologcial Analysis: Social Sciences Academic Press 2008.

36. Hong YB, Zhao YD. From Capital to Habits: Stratification of Chinese Urban Family Educational Patterns. Sociological Study (in Chinese). 2014;4:73-93.

37. Payne LO, Galloway AT, Webb RM. Parental Use of Differential Restrictive Feeding Practices with Siblings. International Journal of Pediatric Obesity. 2011;6:e540-e46.

38. Tschann JM, Gregorich SE, Penilla C, et al. Parental Feeding Practices in Mexican American Families: Initial Test of An Expanded Measure. The International Journal of Behavioral Nutrition Physical Activity. 2013;10:1-11.

39. Blissett J. Haycraft. Parental Eating Disorder Symptoms and Observations of Mealtime Interactions with Children. J Psychosom Res. 2011;70:368-71.

40. Zhang L, Mclntosh WA. Children's Weight Status and Maternal and Paternal Feeding Practices. J Child Health Care. 2011;15:389-400.

41. Johannsen DL, Johannsen NM, Specker BL. Influence of Parents' Eating Behaviors and Child Feeding Practices on Children's Weight Status. Obesity. 2006;14:431-39.

42. Berge J, Wall M, Larson $\mathrm{N}$, et al. The unique and additive associations of family functioning and parenting practices with disordered eating behaviors in diverse adolescents. J Behav Med. 2014;37:205-17.

43. Berge J, Meyer C, MacLehose R, et al. Nonresident parental influence on adolescent weight and weight-related behaviors: similar or different from resident parental influence? International Journal of Behavioral Nutrition Physical Activity. 2014;11:131.

44. Berge J, Wall M, Bauer K, et al. Parenting characteristics in the home environment and adolescent overweight. Obesity. 2009;17:1-8.

45. Chen F, Yang Y, Liu G. Social Change and Socioeconomic Disparities in Health over the Life Course in China: A Cohort Analysis. Am Sociol Rev. 2010;75:126-50.

46. Zhen S, Ma Y, Zhao Z, et al. Dietary pattern is associated with obesity in Chinese children and adolescents: data from China Health and Nutrition Survey (CHNS). Nutr J. 2018;17:68.

47. Derks IP, Tiemeier H, Sijbrands EJ, et al. Testing the direction of effects between child body composition and restrictive feeding practices: Results from a population-based cohort. Am J Clin Nutr. 2017;106:783-90.

48. Liszewskaa N, Scholzb U, Radtkeb T, et al. Bi-directional associations between parental feeding practices and children's body mass in parent-child dyads. Appetite. 2018;129:192-97. 
Tables

Page 9/14 


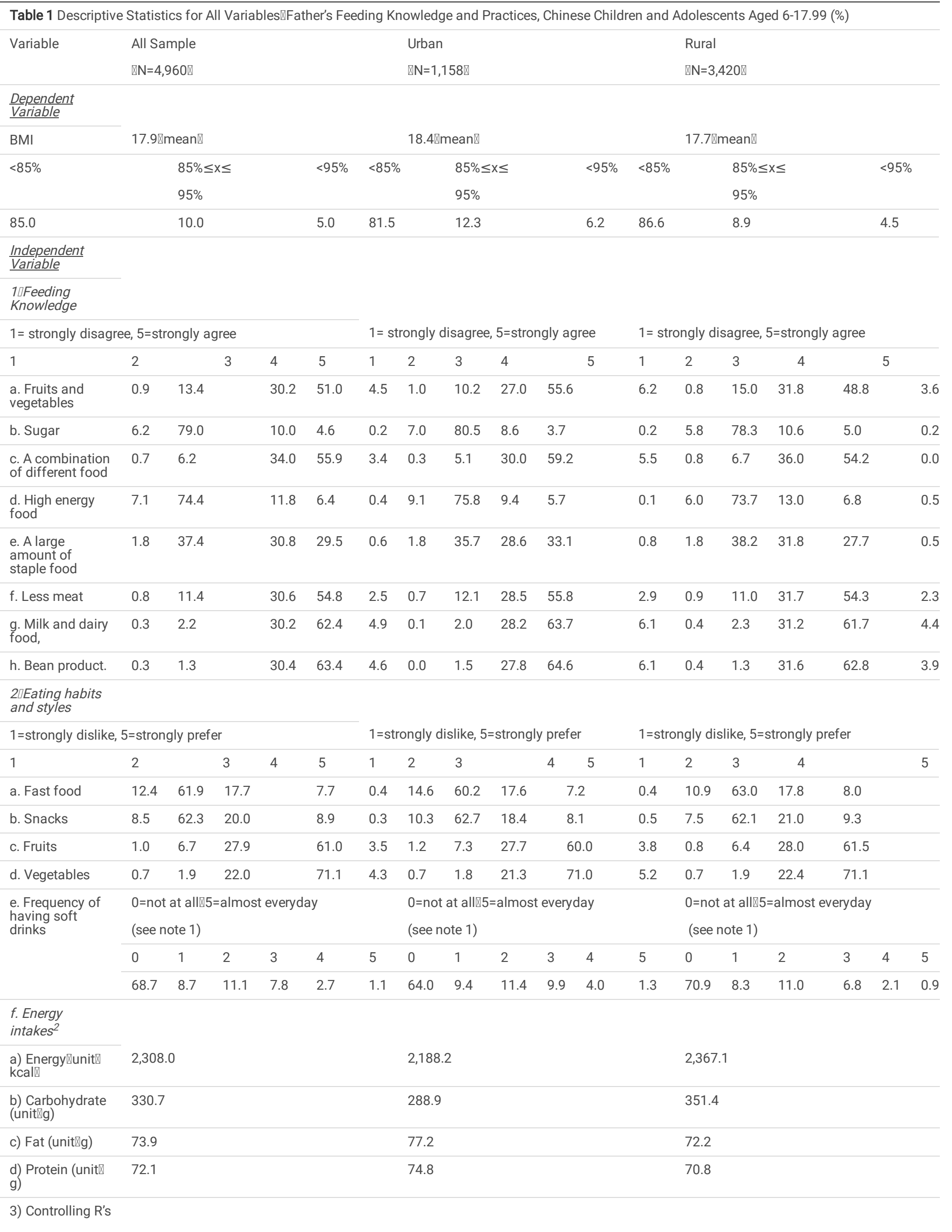




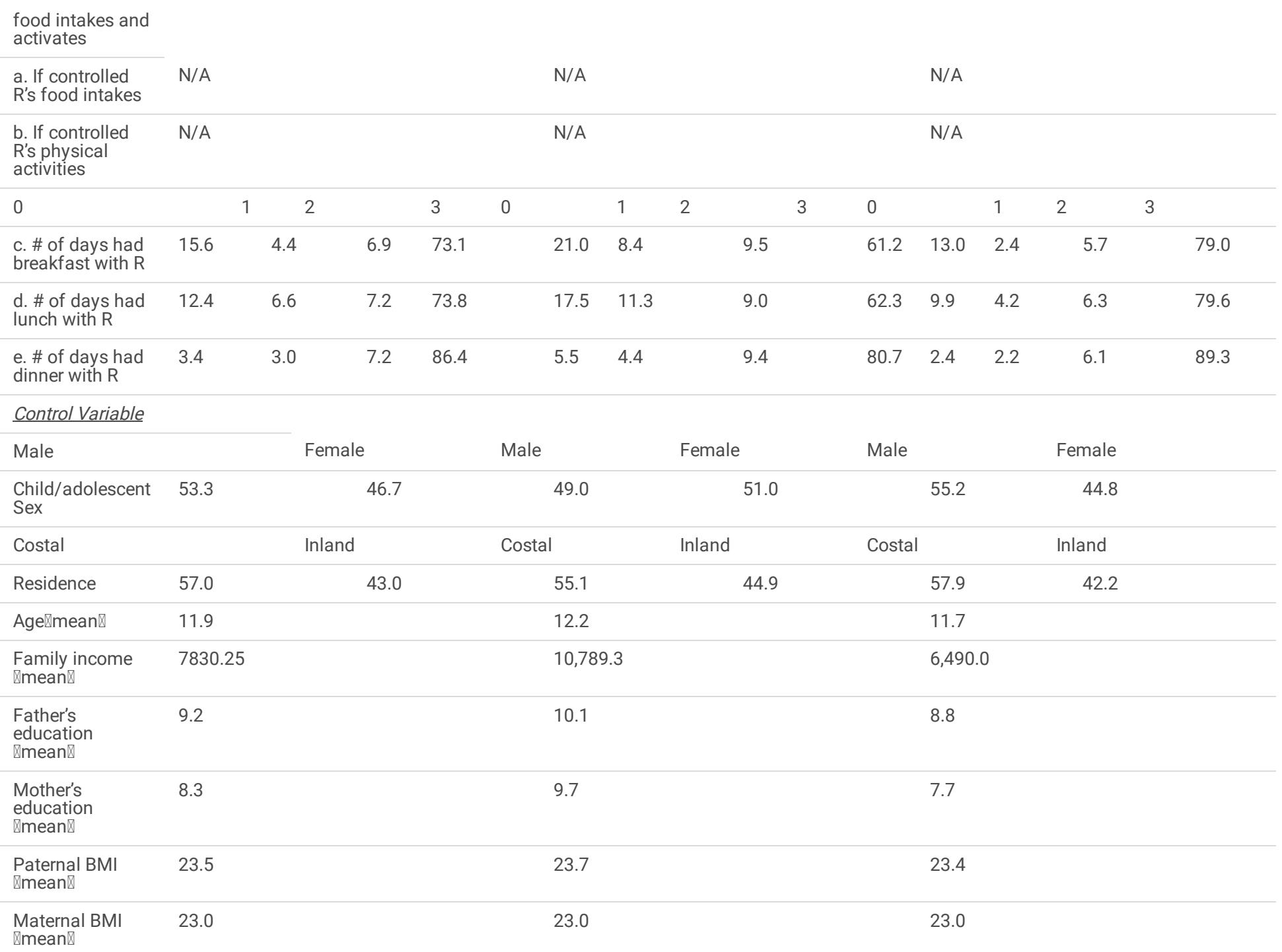

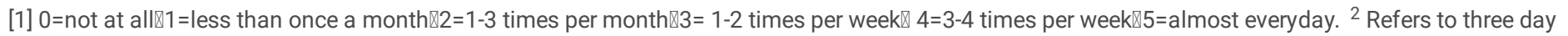
average.

Note: $\mathrm{R}$ referred to the respondent. Some sub-categories may not add up to $100 \%$ due to rounding. Sources $22004,2006,2009$ and 2011 CHNS surveys. 


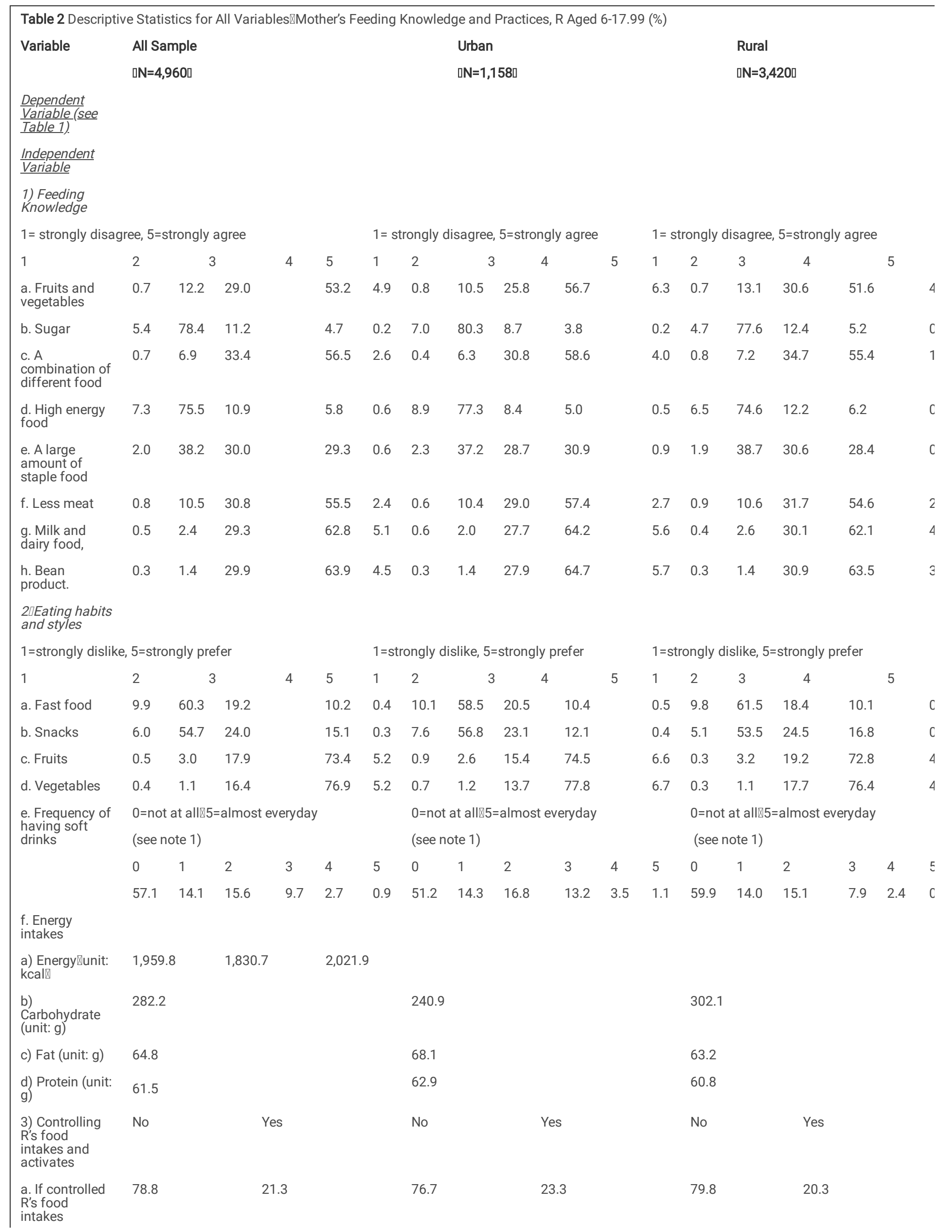




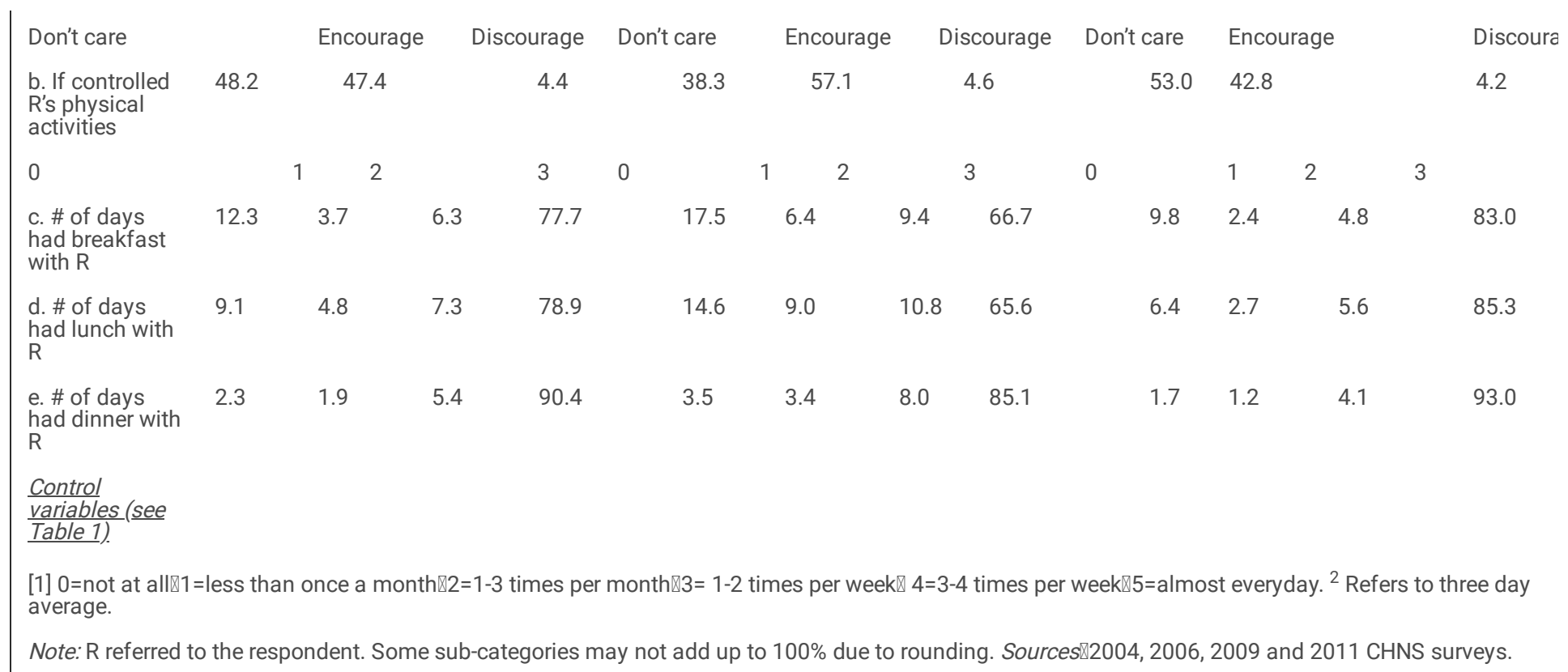




\begin{tabular}{|c|c|c|c|c|c|c|}
\hline \multirow[t]{2}{*}{ Variables } & \multicolumn{2}{|c|}{ All Sample } & \multicolumn{2}{|c|}{ Urban Sample } & \multicolumn{2}{|c|}{ Rural Sample } \\
\hline & $\begin{array}{l}\text { Model } 1 \\
\text { (Fathers) }\end{array}$ & $\begin{array}{l}\text { Model } 2 \\
\text { (Mothers) }\end{array}$ & $\begin{array}{l}\text { Model } 3 \\
\text { (Fathers) }\end{array}$ & $\begin{array}{l}\text { Model } 4 \\
\text { (Mothers) }\end{array}$ & $\begin{array}{l}\text { Model } 4 \\
\text { (Fathers) }\end{array}$ & $\begin{array}{l}\text { Model } 5 \\
\text { (Mothers) }\end{array}$ \\
\hline \multicolumn{7}{|l|}{ Independent variables } \\
\hline \multicolumn{7}{|l|}{ 1) Feeding Knowledge } \\
\hline a. Eating vegetables is good for health & -.03 & -.08 & -.07 & -.14 & -.01 & -.02 \\
\hline b. Eating sugar is good for health & -.17 & -.16 & -.01 & -.17 & -.28 & -.14 \\
\hline c. Eating a variety of food is good for health & $-.18^{\star}$ & $-.24^{\star *}$ & -.21 & $-.30 *$ & -.16 & -.21 \\
\hline d. Eating high-energy food is good for health & -.10 & .00 & -.23 & .06 & -.02 & .00 \\
\hline e. Eating a large amount of staple food is good for health & .05 & $.14^{*}$ & .01 & .02 & .08 & $.26 \star \star$ \\
\hline f. Eating less fat and meat is good for health & .05 & .10 & .15 & .25 & -.02 & .03 \\
\hline g. Eating bean product is good for health & .06 & .07 & -.12 & .00 & .19 & .17 \\
\hline \multicolumn{7}{|l|}{ 2) Food preferences and eating styles } \\
\hline a. Eating fruits frequently & -.01 & .14 & .08 & .20 & -.05 & .07 \\
\hline b. Eating vegetables frequently & -.15 & $-.28^{\star}$ & -.11 & -.27 & -.15 & -.28 \\
\hline c. Frequency drinking soft drinks & -.04 & -.04 & -.06 & .00 & -.04 & -.10 \\
\hline d. Energy intakes & -.01 & .01 & .01 & .01 & -.01 & .01 \\
\hline \multicolumn{7}{|l|}{ 3) Controlling children's eating and activity behaviors } \\
\hline a. If control R's food intakes (ref.=No) & $.50 * \star \star$ & $.81^{\star \star \star}$ & .27 & & & \\
\hline \multicolumn{7}{|l|}{ b. If control R's physical activates (ref.=No) } \\
\hline Yes, encourage more & $.29 \star \star$ & .26 & $.34^{*}$ & & & \\
\hline Yes, encourage less & -.46 & -.40 & -.47 & & & \\
\hline c. Sharing breakfast with children & -.08 & -.03 & -.04 & .07 & -.11 & -.12 \\
\hline d. Sharing lunch with children & -.09 & -.09 & -.08 & $-.19 *$ & -.08 & .02 \\
\hline e. Sharing dinner with children & .18 & .09 & .19 & .09 & .18 & .02 \\
\hline \multicolumn{7}{|l|}{ Control variables } \\
\hline Sex (ref.=female) & .19 & .14 & $.35^{\star}$ & $.40 *$ & .09 & -.03 \\
\hline Area(ref.= inland) & .09 & .07 & .09 & .33 & .06 & -.08 \\
\hline Age & $.18^{\star \star \star}$ & $.18^{\star \star \star}$ & $.16^{\star \star \star}$ & $.16^{\star \star \star}$ & $.19 \star \star \star$ & 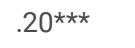 \\
\hline Per capita family income & $.15^{\star \star}$ & $.20 * \star \star$ & .17 & $.24^{\star}$ & .13 & $.18^{\star \star}$ \\
\hline Father's education & .03 & $.06 * \star \star$ & .01 & .05 & .04 & $.07 * \star$ \\
\hline Paternal/maternal BMI & $.16 * \star \star$ & $.14 * \star \star$ & $.17^{\star \star \star}$ & $.13^{\star \star \star}$ & $.15^{\star \star \star}$ & $.15^{\star \star \star}$ \\
\hline Cons & $-7.86^{\star \star \star}$ & $-8.61^{\star \star \star}$ & $-7.58^{\star \star \star}$ & 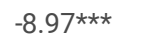 & $-7.95^{\star \star \star}$ & $-8.93^{\star \star \star}$ \\
\hline $\mathrm{N}$ & 3,188 & 3,309 & 1,080 & 1,106 & 2,108 & 2,203 \\
\hline Chi-square & 330.92 & 341.79 & 131.79 & 135.81 & 197.17 & 229.05 \\
\hline Log likelihood & -1231.09 & -1256.40 & -467.54 & -454.85 & -756.68 & -785.89 \\
\hline Nagelkerke R- Squared & 0.12 & 0.12 & 0.12 & 0.13 & 0.12 & 0.13 \\
\hline 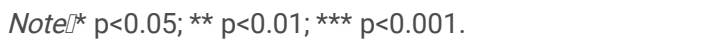 & & & & & & \\
\hline
\end{tabular}

